\title{
Implementation of Guidelines for the Management of Arterial Hypertension. The Impulsion Study
}

\author{
Asterios Karagiannis ${ }^{1}$, Apostolos I. Hatzitolios ${ }^{2}$, Vasilios G. Athyros ${ }^{1}$, Kalliopi Deligianni ${ }^{3}$, \\ Charalambos Charalambous ${ }^{4}$, Christos Papathanakis ${ }^{5}$, Georgios Theodosiou ${ }^{6}$, Theodoros Drakidis ${ }^{7}$, \\ Veronika Chatzikaloudi ${ }^{7}$, Chysanthi Kamilali ${ }^{7}$, Sotirios Matsiras ${ }^{8}$, Athanasios Matziris ${ }^{9}$, \\ Christos Savopoulos ${ }^{2}$, Maria Baltatzi ${ }^{2}$, Jobst Rudolf ${ }^{10}$, Konstantinos Tziomalos ${ }^{11}$ and \\ Dimitri P. Mikhailidis ${ }^{11 * *}$
}

\begin{abstract}
${ }^{1}$ Second Propedeutic Department of Internal Medicine, Medical School, Aristotle University of Thessaloniki, Hippocration Hospital, Thessaloniki, Greece, ${ }^{2}$ First Propedeutic Department of Internal Medicine, Medical School, Aristotle University of Thessaloniki, AHEPA Hospital, Thessaloniki, Greece, ${ }^{3}$ Department of Internal Medicine, Katerini Hospital, Katerini, Greece, ${ }^{4}$ Department of Internal Medicine, Phychiatric Hospital, Thessaloniki, Greece, ${ }^{5}$ Health Centre of Orestiada, Orestiada, Greece, ${ }^{6}$ Department of Internal Medicine, Edessa Hospital, Edessa, Greece, ${ }^{7}$ Health Centre of Sidirokastro, Sidirokastro, Greece, ${ }^{8}$ Health Centre of Chalastra, Chalastra, Greece, ${ }^{9}$ Health Centre of Langadas, Langadas, Greece, ${ }^{10}$ Stroke Unit, Department of Neurology, Papageorgiou Hospital, Thessaloniki, Greece, ${ }^{11}$ Department of Clinical Biochemistry, Royal Free Hospital Campus, University College Medical School, University College London, Pond Street, London, UK
\end{abstract}

\begin{abstract}
This study assessed the effects of a pilot best practice implementation enhancement program on the control of hypertension. We enrolled 697 consecutive known hypertensive patients with other vascular risk factors but free from overt vascular disease. There was no "control" group because it was considered unethical to deprive high-risk patients from "best medical treatment". Following a baseline visit, previously trained physicians aimed to improve adherence to lifestyle measures and drug treatment for hypertension and other vascular risk factors. Both at baseline and at study completion (after 6 months), a 1-page form was completed showing if patients achieved treatment targets. If not, the reasons why were recorded. This program enhanced compliance with lifestyle measures and increased the use of evidence-based medication. There was a substantial increase in the number of patients who achieved treatment targets for blood pressure $(\mathrm{p}<0.0001)$ and other vascular risk factors. In non-diabetic patients $(\mathrm{n}=585)$, estimated vascular risk (PROCAM risk engine) was significantly reduced by $41 \%(\mathrm{p}<0.0001)$. There was also a $12 \%$ reduction in vascular risk according to the Framingham risk engine but this did not achieve significance $(\mathrm{p}=0.07)$. In conclusion, this is the first study to increase adherence to multiple interventions in hypertensive patients on an outpatient basis, both in primary care and teaching hospitals. Simple, relatively low cost measures (e.g. educating physicians and patients, distributing printed guidelines/brochures and completing a 1-page form) motivated both physicians and patients to achieve multiple treatment goals. Further work is needed to establish if the improvement observed is sustained. [ClinicalTrials.gov NCT00416611].
\end{abstract}

Key Words: Hypertension, treatment, control, best practice, vascular risk factors.

\section{INTRODUCTION}

Cardiovascular disease (CVD) morbidity and mortality show a continuous relationship with both systolic and diastolic blood pressure (BP) levels, without any evidence of a threshold down to at least $115 / 75 \mathrm{mmHg}$ [1]. Hypertension is considered a major modifiable risk factor for stroke and also increases the risk for coronary heart disease (CHD), heart failure, chronic kidney disease (CKD) and peripheral arterial disease [2]. Randomized placebo-controlled trials showed that BP lowering is associated with a reduction in the risk of

\footnotetext{
*Address correspondence to this author at the Department of Clinical Biochemistry, Royal Free Hospital Campus, University College Medical School, University College London, Pond Street, London NW3 2QG, UK; Tel: +44 207830 2258; Fax: +44 207830 2235;

E-mail: MIKHAILIDIS @aol.com

\#All authors listed at the end of the article in the Co-investigators section.
}

fatal and non-fatal stroke (by about 30-40\%), while CHD events are reduced to a lesser extent (by about 20\%) [3-8]. Comparative studies showed that for a similar BP lowering, differences in vascular risk reduction between various drug classes are small $[7,9]$.

According to the National Health and Nutrition Examination Survey (NHANES) data, the prevalence of hypertension increased significantly between 1988 and 2004 [10]. Between 1988 to 1994 and 1999 to 2004, BP control increased in men from $39 \%$ to $51 \%(\mathrm{p}<0.05)$ but did not change significantly in women (35\% to 37\%) [10]. Control rates were lower in persons older than 70 years and in patients with type 2 diabetes mellitus (T2DM) or CKD [10]. Similar hypertension control rates were recently reported in Europe [11].

In the present study we assessed whether a best practice implementation enhancement program could improve con- 
trol of hypertension and other vascular risk factors in hypertensive patients without clinically overt vascular disease.

\section{STUDY DESIGN AND METHODS}

The IMPULSION (Implementation of guidelines for the management of arterial hypertension). Study was conducted during 2006-2007 under the auspices of the Regional (Bureau) Authority of the Ministry of Health for Northern Greece-Central Macedonia. The Working Groups for the identification and treatment of hypertension of the Hellenic Atherosclerosis Society and the Greek Society of General Practitioners jointly conducted the study. The study received ethical approval and informed consent was obtained from all patients before enrolment. This study is registered as ClinicalTrials.gov NCT00416611.

Definition of Hypertension, Dyslipidemia, T2DM and Metabolic Syndrome (MetS)

At baseline, BP was measured in both arms by a trained physician using a standard mercury sphygmomanometer after 5 min rest with the subject in the sitting position. The arm with the highest reading was selected $[2,12]$. The mean of 2 measurements, taken $1 \mathrm{~min}$ apart, was recorded in the selected arm. The disappearance of Korotkoff sound (onset of phase 5) was used to define diastolic BP (DBP). All patients were on treatment with antihypertensive medication [13]. Hypertension was considered to be controlled if the BP was $\leq 140 / 90 \mathrm{mmHg}$. In patients with T2DM, BP was considered to be controlled when it was $\leq 130 / 80 \mathrm{mmHg}$ [13].

Patients were considered to have dyslipidemia when: i) low density lipoprotein cholesterol (LDL-C) levels were $<160 \mathrm{mg} / \mathrm{dl}(4.2 \mathrm{mmol} / \mathrm{l}),<130 \mathrm{mg} / \mathrm{dl}(3.4 \mathrm{mmol} / \mathrm{l}),<100 \mathrm{mg} / \mathrm{dl}$ $(2.6 \mathrm{mmol} / \mathrm{l})$ or $<70 \mathrm{mg} / \mathrm{dl}(1.8 \mathrm{mmol} / \mathrm{l})$ in lower risk, moderate/moderately high risk, high risk (CHD or CHD risk equivalents) or very high risk (CHD with T2DM or MetS or smoking) patients, respectively [14], ii) high density lipoprotein cholesterol (HDL-C) levels were $<40 \mathrm{mg} / \mathrm{dl}(1.0 \mathrm{mmol} / \mathrm{l})$ in both genders [15], iii) non-HDL-C levels were $>30 \mathrm{mg} / \mathrm{dl}$ higher than the LDL-C target levels (according to risk status) in patients with triglyceride (TG) levels >200 mg/dl (2.2 $\mathrm{mmol} / \mathrm{l})$ [14], or, iv) patients were on lipid-lowering treatment. Only patients with TG levels $<400 \mathrm{mg} / \mathrm{dl}$ $(4.5 \mathrm{mmol} / \mathrm{l})$ were included in the study, since the Friedewald formula [LDL-C = total cholesterol - $(\mathrm{TG} / 5+\mathrm{HDL}-\mathrm{C})$ in $\mathrm{mg} / \mathrm{dl}]$ was used to calculate LDL-C levels.

According to the American Diabetes Association criteria, patients were considered to have T2DM when the fasting venous plasma glucose levels were $\geq 126 \mathrm{mg} / \mathrm{dl}(7.0 \mathrm{mmol} / \mathrm{l})$ on 2 consecutive assessments or if they were on treatment for T2DM [16].

Participants with 3 or more of the following criteria [according to the National Cholesterol Educational Program Adult Treatment Panel III (NCEP ATP III) report] [17] were considered to have MetS:

1. Waist circumference $(\mathrm{WC})>102 \mathrm{~cm}$ in men and $>88 \mathrm{~cm}$ in women

2. Fasting $\mathrm{TG} \geq 150 \mathrm{mg} / \mathrm{dl}(1.7 \mathrm{mmol} / \mathrm{l})$ or on treatment for TG

3. HDL-C $<40 \mathrm{mg} / \mathrm{dl}(1.0 \mathrm{mmol} / \mathrm{l})$ in men and $<50 \mathrm{mg} / \mathrm{dl}$ $(1.3 \mathrm{mmol} / \mathrm{l})$ in women or on treatment for HDL-C
4. $\mathrm{BP} \geq 130 / 85 \mathrm{mmHg}$ or use of antihypertensive medication

5. Fasting venous plasma glucose $\geq 110 \mathrm{mg} / \mathrm{dl}(6.1 \mathrm{mmol} / \mathrm{l})$ or treatment

\section{Study Design - Study Cohort}

This was a best practice prospective study. Physicians from Health Centres (primary care) or Hospitals (secondary care) recruited consecutive consenting patients with known hypertension, with or without other vascular risk factors, but free of overt CVD at baseline. A total of 697 hypertensive patients were enrolled. Seven additional patients that were planning to move to a region outside the program area did not agree to participate. These 7 patients were not different in their demographic or clinical characteristics from those who agreed to participate. Besides, their number is so small that it could not have changed the baseline status or final outcome. Apart from these 7 patients, no other patient refused to participate.

During the first visit, personal and family history, as well as medication, was recorded in a specially designed 1-page form (Table 1). A physical examination was also carried out. Afterwards, laboratory tests were performed at the hospital following a $12 \mathrm{~h}$ fast, at which time a second physical examination was performed to confirm the clinical findings.

\section{Intervention}

Before study initiation and during the study physicians attended an educational and problem solving program. In all there were 7 meetings. The educational components were presentation of current guidelines for hypertension, dyslipidemia, T2DM, MetS and nutrition (specific diets based on a Greek variation of the Mediterranean diet). Up to date treatment protocols were also discussed. This took 4 meetings. The other 3 meetings were for technical problem solving during the study. To facilitate physician education we supplied current guidelines for the treatment of hypertension and other risk factors and an information brochure for the patients providing advice on lifestyle measures. All these documents (Patient Data Form, Guidelines for the Physician, Patient Brochure) were written using a computer and photocopies were distributed. This was deemed to be a low cost procedure. The physicians agreed to participate as part of their continuing medical education program. They also wanted to have more patients at goal for CVD risk factors.

During the study, an intensification of treatment in terms of lifestyle advice, new drugs or titration of already prescribed drugs was implemented aiming to reach multiple treatment targets. Physicians also advised each patient to improve compliance with a healthier lifestyle and drug treatment. The lifestyle changes included smoking cessation, weight reduction, increased physical activity, decreased salt intake, moderate alcohol consumption and a Mediterranean diet. The patients were advised as to how often they should consume non-refined cereals (e.g. whole grain bread, pasta and rice), potatoes, fruits, vegetables, legumes, fish, red meat and products, poultry, full fat dairy products (cheese, yoghurt and milk), olive oil in cooking and alcoholic beverages [18]. Compliance to the Mediterranean diet was assessed using a 10-unit scale. 
Table 1. Patient Data Form

\section{PATIENT DATA}
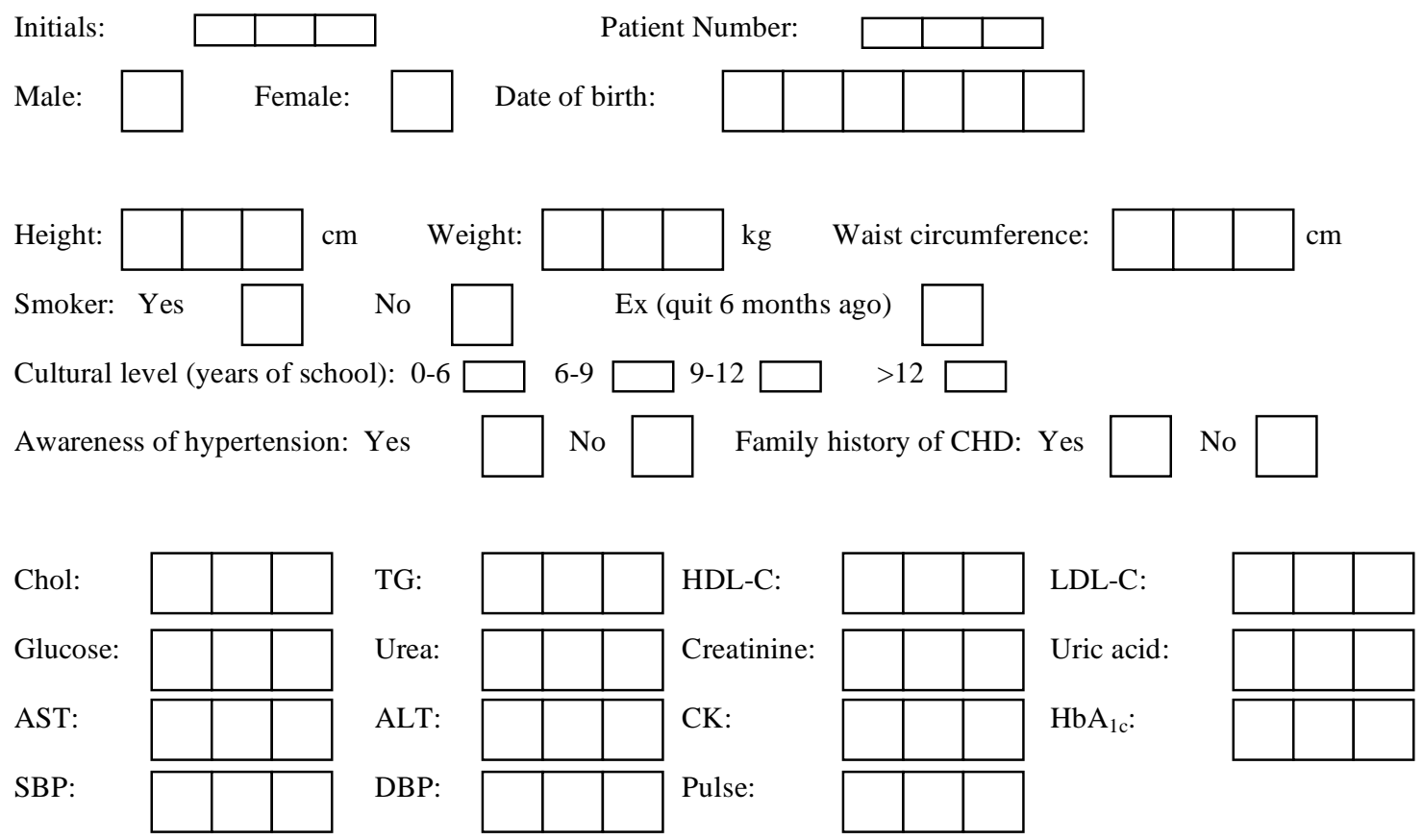

Antihypertensive Drug Treatment:

\begin{tabular}{|c|c|c|c|c|c|}
\hline Diuretic: & Yes & No & Combination: & Yes & No \\
\hline ACEI: & Yes & No & Antidiabetics: & Yes & No \\
\hline ARB: & Yes & No & Statin: & Yes & No \\
\hline$\beta$-blocker: & Yes & No & Fibrate: & Yes & No \\
\hline Ca-blocker: & Yes & No & ASA: & Yes & No \\
\hline Other: & Yes & No & Clopidogrel: & Yes & No \\
\hline
\end{tabular}

Is the patient on target for BP? Yes

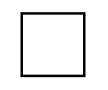

No

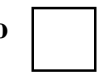

If not what did you do?

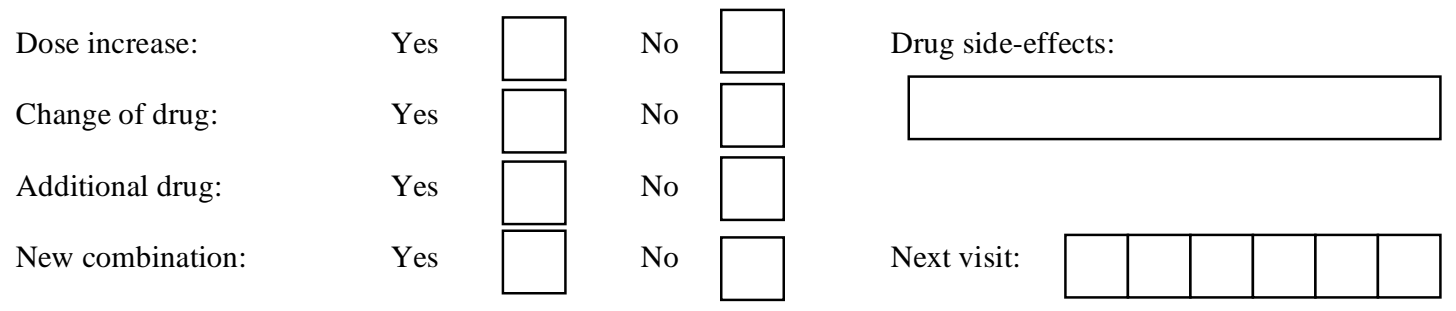

\section{Follow-up}

In Greece monthly visits are required by health care providers for the renewal (refill) of prescriptions by general practitioners or outpatient clinic physicians. Consequently, patients had to visit their physician every month. At the $6^{\text {th }}$ treatment month (the final visit) physicians completed the same form for each patient that included 2 more questions. Does the patient still have hypertension? And if yes, what did the physician do about it? Physicians were aware of this question from visit 1 and we believe that this was a motivational factor. 
There was no "control" group because all patients had hypertension, as well as other vascular risk factors. It was therefore deemed unethical to deprive them of "best medical treatment". Any changes at the final visit were compared with baseline values. The estimated vascular risk was 11.2 and $12.2 \%$ at baseline in non-diabetic patients [assessed with the PROspective CV Münster (PROCAM) and Framingham risk engine, respectively; Table 2] but this was calculated using "on treatment" values. In this context, all patients were taking at least 1 antihypertensive drug and $24.8 \%$ of the whole study population were on statins. Furthermore, $16 \%$ had T2DM (a CHD risk equivalent $[14,17]$ ) and about $43 \%$ had MetS.

\section{Laboratory-Based Assessment}

After an overnight $12 \mathrm{~h}$ fast, serum total cholesterol, HDL-C, TG, transaminases, creatinine and uric acid levels and plasma glucose levels were measured using an Olympus AU 560 autoanalyser (Medicon Hellas, Athens, Greece) and respective reagents (Olympus Diagnostica GmbH, Clare, Ireland). LDL-C was calculated using the Friedewald for-

Table 2. Patient Characteristics at Baseline and at the End of the Study (i.e. After 6 Months)

\begin{tabular}{|c|c|c|c|}
\hline & Baseline $\mathrm{n}=697$ & End of Study $n=697$ & $\mathbf{P}$ \\
\hline Age (years \pm SD) & $59 \pm 8$ & & \\
\hline \multicolumn{4}{|l|}{ Years of education (\%) } \\
\hline$<6$ & 54.6 & & \\
\hline University education & 6.9 & & \\
\hline Body weight (kg) & $82 \pm 12$ & $79 \pm 13$ & NS \\
\hline Waist circumference $(\mathrm{cm})$ & $97 \pm 13$ & $96 \pm 9$ & NS \\
\hline Smoking $(\%)$ & 33.6 & 32.2 & NS \\
\hline At diastolic BP target (\%) & 32.7 & 64.2 & $<0.0001$ \\
\hline At both systolic and diastolic BP target (\%) & 19.3 & 49.2 & $<0.0001$ \\
\hline Dyslipidemia (\%) & 59.7 & 53.6 & NS \\
\hline Total cholesterol (mg/dl) & $223 \pm 36$ & $205 \pm 28$ & $<0.0004$ \\
\hline Triglycerides (mg/dl) & $153 \pm 44$ & $134 \pm 32$ & $<0.002$ \\
\hline LDL-C (mg/dl) & $143 \pm 31$ & $125 \pm 23$ & $<0.0001$ \\
\hline HDL-C (mg/dl) & $44 \pm 13$ & $45 \pm 14$ & NS \\
\hline On lipid targets (in the whole population, $\mathrm{n}=697)(\%)$ & 44.6 & 72.8 & $<0.0001$ \\
\hline Serum creatinine $(\mathrm{mg} / \mathrm{dl})$ & $0.90 \pm 0.34$ & $0.89 \pm 0.27$ & NS \\
\hline Serum uric acid $(\mathrm{mg} / \mathrm{dl})$ & $5.5 \pm 2.4$ & $5.3 \pm 2.6$ & NS \\
\hline AST (IU/l) & $24 \pm 9$ & $23 \pm 8$ & NS \\
\hline $\operatorname{ALT}(\mathrm{IU} / \mathrm{l})$ & $25 \pm 11$ & $24 \pm 9$ & NS \\
\hline 10-year patient risk PROCAM \% (in non-diabetic patients, $n=585$ ) & 11.2 & $6.6(-41 \%)$ & $<0.0001$ \\
\hline 10 -year patient risk Framingham $\%$ (in non-diabetic patients, $n=585$ ) & 12.2 & $10.7(-12 \%)$ & NS \\
\hline
\end{tabular}

BP, blood pressure; LDL-C, low density lipoprotein cholesterol; HDL-C, high density lipoprotein cholesterol; HbA 1 , glycated hemoglobin; AST, aspartate transaminase; ALT, alanine transaminase; PROCAM, prospective CV münster study; MetS, metabolic syndrome; NS, not significant. 
mula. Glycated hemoglobin $\left(\mathrm{HbA}_{1 c}\right)$ was determined in diabetic patients with high performance liquid chromatography (HPLC) using the Menarini Diagnostics (Menarini, Greece) reagents (reference range: 4.2-6.5\%). All hospital laboratories participate in internal and external quality control schemes.

\section{PROCAM and Framingham 10-Year Risk Estimates}

The PROCAM Trial risk engine [http://www.chdtaskforce.com] calculates the 10-year risk for fatal or nonfatal myocardial infarction (MI), taking into consideration age, LDL-C, HDL-C, TG, smoking habit (including exsmokers), fasting blood glucose, systolic BP (SBP), current antihypertensive treatment and family history of premature CVD.

The Framingham risk engine [http://www.chdtaskforce.com] does not consider impaired fasting glucose, ex-smoking, high TG levels and family history of premature CVD when calculating the 10 -year risk. Moreover, when the 10 -year risk is $>30 \%$ the program does not provide an exact number.

Since we are comparing pre- with post-intervention calculated risk we allowed an additional \pm 5 years of age beyond the limits set by the PROCAM risk engine. This procedure allowed us to compare a greater number of patients.

\section{Statistical Analysis}

Analyses were carried out using the SPSS 12.0 software (SPSS Inc., Chicago, IL). All variables had a normal distribution (assessed with the Kolmogorov-Smirnov test) and are reported as mean and standard deviation (SD). The paired samples t-test and Chi-square test were used to evaluate changes in continuous and categorical variables, respectively. A two tailed $\mathrm{p}<0.05$ was considered significant.

\section{RESULTS}

\section{Baseline Data}

The baseline characteristics of the 697 hypertensive patients recruited in the study are shown in Tables $\mathbf{2}$ and $\mathbf{3}$. Twenty seven additional patients attended the baseline visit but did not attend the final visit (after 6 months) and are not included in the final analysis. These 27 patients represent $3.9 \%$ of the recruited population.

As already mentioned, all patients were known hypertensives and were receiving at least 1 antihypertensive drug; the mean number of antihypertensive drugs per patient was 1.4. At baseline, $21.8 \%$ of patients were on target for SBP (140 $\mathrm{mmHg}), 32.7 \%$ for DBP $(90 \mathrm{mmHg}$ ) and $19.3 \%$ for both SBP and DBP (add to Table 2). Although the prevalence of dyslipidemia was $59.7 \%$, only $24.8 \%$ of patients were receiving statins. At baseline, $44.6 \%$ of the whole population was at their lipid targets. Among patients on statins, $17.2 \%$ were at their target. At baseline, $12.6 \%$ of patients were taking aspirin (ASA).

\section{Treatment and Control of Hypertension and Other Vascular Risk Factors}

As shown in Tables $\mathbf{2}$ and $\mathbf{3}$, the vascular risk factor profile improved significantly during the 6-month follow-up associated with a greater compliance to lifestyle advice (there was a 2-unit increase in adherence to the recommended diet) and a more aggressive pharmacological intervention.

At the end of the study $54.7 \%$ of the patients were on target for SBP, $64.2 \%$ for DBP and $49.2 \%$ for both SBP and DBP ( $<<0.0001$ for all comparisons $v s$. baseline). Compared with BP at baseline, average SBP was reduced by $18 \mathrm{mmHg}$ $(\mathrm{p}<0.0001)$ and DBP by $9 \mathrm{mmHg}(\mathrm{p}<0.0001)$. The mean number of antihypertensive drugs per patient increased from 1.4 to $2.8(\mathrm{p}<0.0001)$ and the use of fixed combinations of antihypertensive drugs increased from $20.3 \%$ to $37.2 \%$ $(\mathrm{p}<0.0001)$.

The prevalence of dyslipidemia at the end of the study decreased by $10.2 \%$ (53.6\% vs. $59.7 \%$ at baseline, $\mathrm{p}=0.12$ ). There was a significant $58.1 \%$ increase in the percentage of patients on statins (from $24.8 \%$ to $39.2 \%, \mathrm{p}<0.0001$ ). At the end of the study, $72.8 \%$ of the whole population was at their lipid targets ( $\mathrm{p}<0.0001$ compared with baseline). Moreover, $68.8 \%$ of patients on statins achieved their targets $(p<0.0001$ compared with baseline).

There was a significant improvement in the glycemic control in diabetic patients; $\mathrm{HbA}_{1 \mathrm{c}}$ decreased by $18 \%(6.1 \%$ vs. $7.4 \%$ at baseline, $\mathrm{p}<0.0001)$. The prevalence of $\mathrm{T} 2 \mathrm{DM}$ at the end of study decreased by $7.5 \%(14.8 \% v s .16 \%$ at baseline, $\mathrm{p}=0.09$ ). At the end of the study, $14.2 \%$ of patients were on antidiabetic drugs and $0.6 \%$ were only on diet.

There was an increase in the use of ASA by $47 \%$ (18.5\% vs. $12.6 \%$ at baseline, $\mathrm{p}<0.0001)$.

There was a reduction in the incidence of MetS by $23 \%$ in men $(29.3 \%$ vs. $37.8 \%$ at baseline, $\mathrm{p}<0.0001)$ and by $26 \%$ in women $(34.2 \%$ vs. $45.9 \%$ at baseline, $\mathrm{p}<0.0001)$.

\section{Framingham and PROCAM 10-Year CVD Risk Esti- mates}

In patients without T2DM $(\mathrm{n}=585,84 \%$ of the study population), the estimated 10-year CHD risk according to the PROCAM risk engine was significantly reduced by $41 \%$ (6.6\% vs. $11.2 \%$ at baseline, $\mathrm{p}<0.0001)$. The estimated 10 year risk according to the Framingham risk engine in the same population was reduced by $12 \%(10.7 \%$ vs. $12.2 \%$ at baseline, $\mathrm{p}=0.07)$. We did not estimate the vascular risk in patients with T2DM ( $\mathrm{n}=112,16 \%$ of the study population) because T2DM is considered a CHD risk equivalent (estimated 10-year risk > 20\%).

\section{Safety and Tolerability}

Medication was well tolerated and the only reported adverse effects that occurred in more than $2 \%$ of the participants were dry cough in users of angiotensin converting enzyme inhibitors (mainly) and of angiotensin receptor blockers (less frequently), as well as ankle oedema in users of calcium antagonists.

\section{DISCUSSION}

Our pilot program was effective at implementing multifactorial evidence-based treatment in hypertensive patients, with or without other vascular risk factors, and free of CVD at baseline. Lifestyle measures and aggressive pharmacological treatment was associated with a significant increase in the proportion of patients reaching target for SBP (from 
Table 3. Drug Treatment at Baseline and at the End of the Study (i.e. After 6 Months)

\begin{tabular}{|l|l|l|l|}
\hline & Baseline $\mathbf{n = 6 9 7}$ & End of Study n=697 & $\mathbf{p}$ \\
\hline \hline Diuretics & 34.5 & 48.7 & $<0.0001$ \\
\hline ACEIs & 30.3 & 49.6 & $<0.0001$ \\
\hline ARBs & 29.6 & 45.2 & $<0.0001$ \\
\hline Beta-blockers & 24.3 & 31.7 & NS \\
\hline Calcium antagonists & 29.8 & 43.5 & $<0.0001$ \\
\hline Fixed combinations & 20.3 & 37.2 & $<0.0001$ \\
\hline Antidiabetic drugs & 13.6 & 14.2 & NS \\
\hline Statins & 24.8 & 39.2 & $<0.0001$ \\
\hline Fibrates & 1.3 & 1.8 & NS \\
\hline Aspirin & 12.6 & 18.5 & $<0.0001$ \\
\hline
\end{tabular}

All numbers express percent of patients.

ACEIs, angiotensin converting enzyme inhibitors; ARBs, angiotensin receptor blockers; NS, not significant.

$21.8 \%$ to $54.7 \%$ ), for DBP (from $32.7 \%$ to $64.2 \%$ ) and for both SBP and DBP (from $19.3 \%$ to $49.2 \%$ ) ( $\mathrm{p}<0.0001$ for all comparisons). There was also a $41 \%$ reduction in estimated 10 -year CHD risk according to the PROCAM risk engine in non-diabetic patients (from $11.2 \%$ to $6.6 \%$; $<<0.0001$ ). In the same population, estimated CHD risk according to the Framingham risk engine also decreased by $12 \%$ but this fall did not achieve significance $(\mathrm{p}=0.07)$. Thus, it is possible that engines incorporating several additional variables (e.g. PROCAM) capture the vascular risk reduction achieved by a multifactorial approach in a more obvious manner than other calculators that consider fewer factors (e.g. Framingham). Whether this means that new broad based risk calculators are required to accurately assess multifactorial approaches to vascular risk reduction remains to be established.

The present study is part of 4 pilot best practice implementation enhancement programs aimed at improving risk factor control in 4 different populations of patients with: (i) hypertension (the present study), (ii) dyslipidemia [Hatzitolios et al, unpublished observations], (iii) MetS [19], or, (iv) T2DM [Athyros et al, unpublished observations]. These programs were similarly effective.

Large surveys in the US, Canada and Europe (Germany, Sweden, England, Spain and Italy) showed that only $29 \%$, $17 \%$ and $10 \%$ of hypertensive patients, respectively, had BP levels less than $140 / 90 \mathrm{mmHg}$ [20]. These findings might be explained by the more aggressive guidelines for hypertension treatment in the US compared with Europe. A recent cross-sectional analysis of the 2004 data from CardioMonitor, an ongoing survey in ambulatory patients with CVD in the US and in 5 European countries (Germany, France, England, Spain and Italy) showed an improvement in control rates [11]. The rate of hypertension control $(<140 / 90 \mathrm{mmHg})$ was $63 \%$ in US and $31-46 \%$ in Europe [11]. Several studies evaluated hypertension control rates in Greece [21-25]. In 2001, the Greek component of the European Prospective Investigation into Cancer and nutrition (EPIC) study (26, 913 volunteers from several regions of Greece) showed that BP was controlled only in $15.2 \%$ of hypertensive patients [21]. In the Attica study (carried out between 2001 and
2002), only $34 \%$ of treated hypertensive patients were adequately controlled [22]. Two smaller regional studies showed that among treated hypertensive patients, 49.5 and $49.1 \%$ (of 344 and 103 treated patients, respectively) were controlled $[23,24]$. In the Hypertension Study in General Practice in Hellas (HYPERTENSHELL; 11, 950 participants), which was conducted during 2002-2004 across Greece, 32.8\% of treated hypertensive patients were adequately controlled [25]. Most of these levels of control are below those achieved in the current study (i.e. $49.2 \%$ ).

The 2003 and 2007 European Society of Hypertension / European Society of Cardiology guidelines state that the management of hypertension should depend on the estimated global vascular risk $[13,26]$. This is based on the fact that only $20 \%$ of hypertensive patients have hypertension alone while the majority has 1 or more additional risk factors [27, 28]. This coexistence of risk factors, which was also evident in our study, produces a total vascular risk that is greater than the sum of the individual factors [29, 30]. It is estimated that in patients with BP of 140-159/90-99 $\mathrm{mmHg}$ and at least 1 additional risk factor, reducing SBP by $12 \mathrm{mmHg}$ for 10 years will prevent 1 death for every 11 treated hypertensive patients [31].

In our study, $59.7 \%$ of hypertensive patients had dyslipidemia at baseline. The increase in the use of statins (from $24.8 \%$ to $39.2 \%, \mathrm{p}<0.0001)$ contributed to the significantly improved lipid profile (total cholesterol, LDL-C and TG but not HDL-C levels). The co-existence of hypertension and dyslipidemia confers a greater increase in vascular risk than would be expected with either risk factor alone [32]. Two trials evaluated the benefits associated with the use of statins specifically in hypertensive patients. In the Antihypertensive and Lipid-Lowering Treatment to Prevent Heart Attack Trial - Lipid-Lowering Trial (ALLHAT-LLT) (10, 355 hypertensive patients), pravastatin $(40 \mathrm{mg} / \mathrm{d})$ did not reduce CHD events, stroke and all cause mortality significantly more than "usual care" [33]. In contrast, in the Anglo-Scandinavian Cardiac Outcomes Trial - Lipid Lowering Arm (ASCOTLLA; 10, 305 hypertensive patients with at least 3 other vascular risk factors but free of CHD), atorvastatin $(10 \mathrm{mg} / \mathrm{d})$ 
significantly reduced vascular events $(36 \% ; \mathrm{p}=0.0005)$ and stroke (27\%; $\mathrm{p}=0.024)$ compared with placebo [34]. This discrepancy may be related to several factors, among which is the extent of LDL-C lowering, which was greater in the ASCOT-LLA trial (17 vs. 29\% relative reduction) [33, 34]. A recent meta-analysis showed that statin therapy reduces vascular morbidity and mortality to the same extent in hypertensive and normotensive patients [35]. There is evidence in secondary prevention that the combination of a statin with angiotensin converting enzyme inhibitors reduces the risk of vascular events more than either drug alone [36]. Furthermore, statins may beneficially influence the BP and some antihypertensive drugs can have a beneficial, neutral or adverse effect on the lipid profile [37-39]. However, we cannot comment on these potential effects using our results.

Current guidelines state that low-dose ASA should be prescribed to hypertensive patients with established CVD, as well as to patients free of CVD but older than 50 years, with a moderate increase in serum creatinine levels or with a high vascular risk [13]. Antiplatelet therapy should be started after achievement of BP control [13]. The Hypertension Optimal Treatment (HOT) trial showed that treatment of hypertensive patients with ASA resulted in a 15\% reduction in major vascular events and a 36\% reduction in acute MI [40]. There was no effect on stroke and no increase in intracerebral haemorrhage but a $65 \%$ increased risk of major hemorrhagic events was observed [40]. The relatively low percentage of patients receiving ASA in our study (18.5\%) may reflect physician reluctance to accept an increased risk of bleeding in a primary prevention setting.

In the UK Prospective Diabetes Study (UKPDS), hypertensive patients with T2DM benefited from intensive blood glucose control mainly in terms of microvascular complications (a 37\% reduction in microvascular complications for each $1 \%$ reduction in $\mathrm{HbA}_{1 \mathrm{c}}$ ) [41]. Other studies showed that improved glycemic control (by lifestyle measures and pharmaceutical interventions) also protects against macrovascular complications [42, 43]. In our study, $16 \%$ of hypertensive patients had T2DM and pharmacologic treatment in combination with lifestyle measures resulted in a significant reduction in $\mathrm{HbA}_{1 \mathrm{c}}$ (from $7.4 \%$ to $6.1 \%, \mathrm{p}<0.0001$ ). The prevalence of T2DM at the end of study decreased by $7.5 \%$ (from $16 \%$ to $14.8 \%, \mathrm{p}=0.09$ ).

In our study, $37.8 \%$ of men and $45.9 \%$ of women had MetS at baseline. The prevalence of MetS in the Western World, including Mediterranean Countries, is high [44] but awareness, treatment and control of MetS and its components remain poor [45-47]. MetS confers an increased risk for vascular morbidity and mortality [48-53] and all-cause mortality [48], even in Mediterranean Countries and in the absence of T2DM and/or clinically evident CVD [49, 50, 54, 55]. The combination of lifestyle interventions and drug treatment for all vascular risk factors in our patients resulted in a significant reduction in the prevalence of MetS (from $37.8 \%$ to $29.3 \%$ in men and from $45.9 \%$ to $34.2 \%$ in women; $\mathrm{p}<0.0001$ for both comparisons).

\section{LIMITATIONS}

In this study there was no control group due to ethical restrictions, as explained above. Each patient acted as his/her own control and had been on a regular treatment regime for an average of 23 months (range: 8-72 months) prior to inclusion in the study. The estimated fall in vascular risk in hypertensive patients was calculated after intervention for 6 months. The observed benefits may decrease if adherence to lifestyle measures and pharmacological treatment deteriorates in the long run. The PROCAM and Framingham calculations were based on a treated population both at baseline and at the end of the study. Twenty seven patients did not attend the final visit (after 6 months). These patients represent only $3.9 \%$ of the baseline population and therefore they were not included in the final analysis. Nevertheless, this should be considered among the limitations of the study.

\section{CONCLUSIONS}

This is the first study to increase adherence to multiple interventions in hypertensive patients on an outpatient basis, both in primary care and teaching hospitals. Simple, relatively low cost measures (e.g. educating physicians and patients, distributing printed guidelines/brochures and completing a 1-page form) were associated with achieving treatment goals for multiple vascular risk factors. Further work is needed to establish the cost effectiveness and long-term benefits of such programs.

\section{CO-INVESTIGATORS}

We thank the following physicians for providing patient data. V. Chatzikaloudi and Ch. Kamilali, Health Centre (HC) of Sidirokastro; P. Psaris, Department of Internal Medicine, Genimatas Hospital, Thessaloniki; E. Papastefanou, Department of Internal Medicine, Serres Hospital; A. Taplidis, Department of Internal Medicine, Naousa Hospital; P. Volonakis, Nephrology Unit, Department of Internal Medicine, Agios Dimitrios Hospital, Thessaloniki; E. Thoma, HC of Deskati; K. Ioannou, HC of Sohos; E. Mandikou, HC of Langadas; K. Gaitanaki, HC of Krya Vrysi; A. El. Hatimi, HC of Zichni; E. Hartamba, HC of Sappes; K. Stefanidou, HC of Skydra; G. Pipertzis, HC of Strymoniko.

\section{ACKNOWLEDGEMENTS}

We thank the following employees of the Regional $(\mathrm{Bu}-$ reau) Authority of the Ministry of Health for Northern Greece-Central Macedonia for their contribution in the study. A. Trichopoulou, Department Head and D. Florinis, A. Kakafika.

\section{DECLARATION OF INTEREST}

This study was conducted independently under the auspices of the Regional Bureau (Authority) of the Ministry of Health for Northern Greece - Central Macedonia. No company or institution supported it financially. Some of the authors have given talks, attended conferences and participated in other trials or advisory boards sponsored by various pharmaceutical companies.

\section{REFERENCES}

[1] Lewington S, Clarke R, Qizilbash N, Peto R, Collins R. Prospective studies collaboration. Age-specific relevance of usual blood pressure to vascular mortality: a meta-analysis of individual data for one million adults in 61 prospective studies. Lancet 2002; 360: 1903-13.

[2] Chobanian AV, Bakris GL, Black HR, et al. Joint National Committee on Prevention, Detection, Evaluation, and Treatment of High Blood Pressure. National Heart, Lung, and Blood Institute; National High Blood Pressure Education Program Coordinating 
Committee. Seventh report of the Joint National Committee on Prevention, Detection, Evaluation, and Treatment of High Blood Pressure. Hypertension 2003; 42: 1206-52.

[3] Turnbull F. Blood pressure lowering treatment Trialists' Collaboration. Effects of different blood-pressure-lowering regimens on major CV events: results of prospectively-designed overviews of randomised trials. Lancet 2003; 362: 1527-35.

[4] Staessen JA, Wang JG, Thijs L. CV prevention and blood pressure reduction: a quantitative overview updated until 1 March 2003. J Hypertens 2003; 21: 1055-76.

[5] Staessen JA, Gasowski J, Wang JG, et al. Risks of untreated and treated isolated systolic hypertension in the elderly: meta-analysis of outcome trials. Lancet 2000; 355: 865-72.

[6] Gueyffier F, Boutitie F, Boissel JP, et al. Effect of antihypertensive drug treatment on $\mathrm{CV}$ outcomes in women and men. A metaanalysis of individual patient data from randomized, controlled trials. The INDANA Investigators. Ann Intern Med 1997; 126: 761-7.

[7] Turnbull F, Neal B, Algert C, et al. Blood pressure lowering treatment Trialists' Collaboration. Effects of different blood pressurelowering regimens on major $\mathrm{CV}$ events in individuals with and without diabetes mellitus: results of prospectively designed overviews of randomized trials. Arch Intern Med 2005; 165: 1410-9.

[8] Neal B, MacMahon S, Chapman N. Effects of ACE inhibitors, calcium antagonists, and other blood-pressure-lowering drugs: results of prospectively designed overviews of randomised trials. Blood pressure lowering treatment Trialists' Collaboration. Lancet 2000; 356: 1955-64.

[9] Mancia G, Grassi G. Systolic and diastolic blood pressure control in antihypertensive drug trials. J Hypertens 2002; 20: 1461-4.

[10] Ostchega Y, Dillon CF, Hughes JP, Carroll M, Yoon S. Trends in hypertension prevalence, awareness, treatment, and control in older U.S. adults: data from the National Health and Nutrition Examination Survey 1988 to 2004. J Am Geriatr Soc 2007; 55: 1056-65.

[11] Wang YR, Alexander GC, Stafford RS. Outpatient hypertension treatment, treatment intensification, and control in Western Europe and the United States. Arch Intern Med 2007; 167: 141-7.

[12] Karagiannis A, Tziomalos K, Krikis N, Sfikas G, Dona K, Zamboulis $\mathrm{C}$. The unilateral measurement of blood pressure may mask the diagnosis or delay the effective treatment of hypertension. Angiology 2005; 56: 565-9.

[13] Mancia G, De Backer G, Dominiczak A, et al. Guidelines for the management of arterial hypertension: The task force for the management of arterial hypertension of the European Society of Hypertension (ESH) and of the European Society of Cardiology (ESC). J Hypertens 2007; 25: 1105-87.

[14] Grundy SM, Cleeman JI, Merz CN, et al. Implications of recent clinical trials for the National Cholesterol Education Program Adult Treatment Panel III guidelines. Circulation 2004; 110: 227-39.

[15] UK HDL-C Consensus Group. Role of fibrates in reducing coronary risk: a UK Consensus. Curr Med Res Opin 2004; 20: 241-7.

[16] Expert Committee on the Diagnosis and the Classification of Diabetes Mellitus. Report of the Expert Committee on the Diagnosis and the Classification of Diabetes Mellitus. Diabetes Care 1997; 20: 1183-97.

[17] The Third Report of the National Cholesterol Education Program (NCEP) Expert Panel on Detection, Evaluation, and Treatment of High Blood Cholesterol In Adults (Adult Treatment Panel III). JAMA 2001: 285: 2486-97.

[18] Panagiotakos DB, Pitsavos C, Stefanadis C. Dietary patterns: A Mediterranean diet score and its relation to clinical and biological markers of cardiovascular disease risk. Nutr Metab Cardiovasc Dis 2006; 16: 559-68

[19] Athyros VG, Karagiannis A, Hatzitolios A, et al. Standardized arrangement for a guideline driven treatment of the metabolic syndrome. The SAGE - METS Study. Curr Med Res Opin 2009; 25: 971-80.

[20] Wolf-Maier K, Cooper RS, Kramer H, et al. Hypertension treatment and control in five European countries, Canada, and the United States. Hypertension 2004; 43: 10-7.

[21] Psaltopoulou T, Orfanos P, Naska A, Lenas D, Trichopoulos D, Trichopoulou A. Prevalence, awareness, treatment and control of hypertension in a general population sample of 26,913 adults in the Greek EPIC study. Int J Epidemiol 2004; 33: 1345-52.

[22] Panagiotakos DB, Pitsavos CH, Chrysohoou C, et al. Status and management of hypertension in Greece: role of the adoption of a Mediterranean diet: the Attica study. J Hypertens 2003; 21: 1483-9.
[23] Stergiou GS, Thomopoulou GC, Skeva II, Mountokalakis TD. Prevalence, awareness, treatment, and control of hypertension in Greece: the Didima study. Am J Hypertens 1999; 12: 959-65.

[24] Skliros EA, Papaioannou I, Sotiropoulos A, Giannakaki G, Milingou M, Lionis C. A high level of awareness but a poor control of hypertension among elderly Greeks. The Nemea primary care study. J Hum Hypertens 2002; 16: 285-7.

[25] Efstratopoulos AD, Voyaki SM, Baltas AA, et al. Prevalence, awareness, treatment and control of hypertension in Hellas, Greece: the hypertension study in general practice in Hellas (HYPERTENSHELL) national study. Am J Hypertens 2006; 19: 53-60.

[26] European Society of Hypertension-European Society of Cardiology Guidelines Committee. European Society of HypertensionEuropean Society of Cardiology guidelines for the management of arterial hypertension. J Hypertens 2003; 21: 1011-53.

[27] Kannel WB. Risk stratification in hypertension: new insights from the Framingham Study. Am J Hypertens 2000; 13(1 Pt 2): $3 \mathrm{~S}-10 \mathrm{~S}$.

[28] Mancia G, Parati G, Borghi C, et al. Hypertension prevalence, awareness, control and association with metabolic abnormalities in the San Marino population: the SMOOTH study. J Hypertens 2006; 24: 837-43.

[29] Asia Pacific Cohort Studies Collaboration. Joint effects of systolic blood pressure and serum cholesterol on CV disease in the Asia Pacific region. Circulation 2005; 112: 3384-90.

[30] Multiple Risk Factor Intervention Trial Research Group. Relationship between baseline risk factors and coronary heart disease and total mortality in the Multiple Risk Factor Intervention Trial. Prey Med 1986; 15: 254-73.

[31] Whitworth JA. World Health Organization, International Society of Hypertension Writing Group. World Health Organization (WHO)/International Society of Hypertension (ISH) statement on management of hypertension. J Hypertens 2003; 21: 1983-92.

[32] Neaton JD, Wentworth D. Serum cholesterol, blood pressure, cigarette smoking, and death from coronary heart disease. Overall findings and differences by age for 316, 099 white men. Multiple Risk Factor Intervention Trial Research Group. Arch Intern Med 1992; 152: 56-64.

[33] ALLHAT Officers and Coordinators for the ALLHAT Collaborative Research Group. The antihypertensive and lipid-lowering treatment to prevent heart attack trial. Major outcomes in moderately hypercholesterolemic, hypertensive patients randomized to pravastatin vs. usual care. JAMA 2002; 288: 2998-3007.

[34] Sever PS, Dahlöf B, Poulter NR, et al. Prevention of coronary and stroke events with atorvastatin in hypertensive patients who have average or lower-than-average cholesterol concentrations, in the Anglo-Scandinavian Cardiac Outcomes Trial--Lipid Lowering Arm (ASCOT-LLA): a multicentre randomised controlled trial. Lancet 2003; 361: 1149-58.

[35] Messerli FH, Pinto L, Tang SS, et al. Impact of systemic hypertension on the $\mathrm{CV}$ benefits of statin therapy--a meta-analysis. Am J Cardiol 2008; 101: 319-25.

[36] Athyros VG, Mikhailidis DP, Papageorgiou AA, et al. Effect of statins and ACE inhibitors alone and in combination on clinical outcome in patients with coronary heart disease. J Hum Hypertens 2004; 18: 781-8.

[37] Milionis HJ, Liberopoulos EN, Elisaf MS, Mikhailidis DP. Analysis of antihypertensive effects of statins. Curr Hypertens Rep 2007; 9: 175-83.

[38] Papadakis JA, Ganotakis ES, Jagroop IA, Mikhailidis DP, Winder AF. Effect of hypertension and its treatment on lipid, lipoprotein (a), fibrinogen, and bilirubin levels in patients referred for dyslipidemia. Am J Hypertens 1999; 12: 673-81.

[39] Karagiannis A, Mikhailidis DP, Kakafika AI, Tziomalos K, Athyros VG. Atenolol: differences in mode of action compared with other antihypertensives. An opportunity to identify features that influence outcome? Curr Pharm Des 2007; 13: 229-39.

[40] Hansson L, Zanchetti A, Carruthers SG, et al. Effects of intensive blood-pressure lowering and low-dose aspirin in patients with hypertension: principal results of the Hypertension Optimal Treatment (HOT) randomised trial. Lancet 1998; 351: 1755-62.

[41] No author listed. Intensive blood-glucose control with sulphonylureas or insulin compared with conventional treatment and risk of complications in patients with type 2 diabetes (UKPDS 33). UK Prospective Diabetes Study (UKPDS) Group. Lancet 1998; 352: $837-53$. 
[42] Chiasson JL, Josse RG, Gomis R, Hanefeld M, Karasik A, Laakso $\mathrm{M}$. Acarbose treatment and the risk of $\mathrm{CV}$ disease and hypertension in patients with impaired glucose tolerance: the STOP-NIDDM trial. JAMA 2003; 290: 486-94.

[43] Gaede P, Vedel P, Larsen N, Jensen GV, Parving HH, Pedersen O. Multifactorial intervention and CV disease in patients with type 2 diabetes. N Engl J Med 2003; 348: 383-93.

[44] Athyros VG, Bouloukos VI, Pehlivanidis AN, et al. The prevalence of the metabolic syndrome in Greece: the MetS-Greece Multicentre Study. Diabetes Obes Metab 2005; 7: 397-405.

[45] Athyros VG, Ganotakis ES, Bathianaki M, et al. Awareness, treatment and control of the metabolic syndrome and its components: a multicentre Greek study. Hellenic J Cardiol 2005; 46: 380-6.

[46] Smith SC Jr, Haslam D. Abdominal obesity, waist circumference and cardio-metabolic risk: awareness among primary care physicians, the general population and patients at risk--the Shape of the Nations survey. Curr Med Res Opin 2007; 23: 29-47.

[47] Wierzbicki AS, Ganotakis ES, Mikhailidis DP. Shape of the Nations survey and attitudes to cardiometabolic risk. Curr Med Res Opin 2007; 23: 25-8.

[48] Isomaa B, Almgren P, Tuomi T, et al. CV morbidity and mortality associated with the metabolic syndrome. Diabetes Care 2001; 24: 683-9.

[49] Lakka HM, Laaksonen DE, Lakka TA, et al. The metabolic syndrome and total and CV disease mortality in middle-aged men. JAMA 2002; 288: 2709-16.
[50] Trevisan M, Liu J, Bahsas FB, Menotti A. Syndrome X and mortality: a population-based study. Risk Factor and Life Expectancy Research Group. Am J Epidemiol 1998; 148: 958-66.

[51] Ford ES. The metabolic syndrome and mortality from CV disease and all-causes: findings from the National Health and Nutrition Examination Survey II Mortality Study. Atherosclerosis 2004; 173: 309-14.

[52] Alexander CM, Landsman PB, Teutsch SM, Haffner SM. Third National Health and Nutrition Examination Survey (NHANES III); National Cholesterol Education Program (NCEP). NCEP-defined metabolic syndrome, diabetes, and prevalence of coronary heart disease among NHANES III participants age 50 years and older. Diabetes 2003; 52: 1210-4.

[53] Athyros VG, Ganotakis ES, Elisaf MS, Liberopoulos EN, Goudevenos IA, Karagiannis A. GREECE-METS Collaborative Group. Prevalence of vascular disease in metabolic syndrome using three proposed definitions. Int J Cardiol 2007; 117: 204-10.

[54] Athyros VG, Mikhailidis DP, Papageorgiou AA, et al. Targeting vascular risk in patients with metabolic syndrome but without diabetes. Metabolism 2005; 54: 1065-74.

[55] Athyros VG, Mikhailidis DP, Papageorgiou AA, et al. Prevalence of atherosclerotic vascular disease among subjects with the metabolic syndrome with or without diabetes mellitus: the METSGREECE Multicentre Study. Curr Med Res Opin 2004; 20: 1691701.

(C) Karagiannis et al.; Licensee Bentham Open.

This is an open access article licensed under the terms of the Creative Commons Attribution Non-Commercial License (http://creativecommons.org/licenses/by$\mathrm{nc} / 3.0 /$ ) which permits unrestricted, non-commercial use, distribution and reproduction in any medium, provided the work is properly cited. 